\title{
Recent Approaches in Guar Gum Hydrogel Synthesis for Water Purification
}

\author{
Sourbh Thakura,b* Bhawna Sharma ${ }^{b}$, Ankit Verma ${ }^{\text {b }}$, Jyoti Chaudhary ${ }^{b}$ Sigitas \\ Tamulevicius ${ }^{\mathrm{a}}$, Vijay Kumar Thakur ${ }^{\mathrm{*} *}$
}

${ }^{a}$ Institute of Materials Science of Kaunas University of Technology, K.Barsausko Str. 59, LT51423 Kaunas, Lithuania

${ }^{b}$ School of Chemistry, Shoolini University, Solan 173212, Himachal Pradesh, India

${ }^{c}$ Enhanced Composites and Structures Center, School of Aerospace, Transport and Manufacturing, Cranfield University, Bedfordshire MK43 OAL, UK

\begin{abstract}
Guar gum based hydrogels have evoked great attention in research as well as in industry for exploring miscellaneous applications in the field of water purification, medicine, agriculture, explosives, cosmetics, textile, paper and food to name a few. In this article, latest modifications for developing guar gum based hydrogels and composite materials for water purification application are extensively reviewed. Regenerative nature of Guar gum hydrogels makes it a better choice for treating waste water as well as other value added applications. Moreover, non-ionic nature makes guar gum an acceptable material for further modifications. In this article, we also presents brief discussion on structure and properties of guar gum.
\end{abstract}

Keywords: Guar gum; hydrogel; composites, dye adsorption; metal ion adsorption; water purification.

*Corresponding authors Email: vijay.kumar@cranfield.ac.uk, thakursourbh@gmail.com, sourbh.sourbh@ktu.lt 


\section{Introduction}

Over past 50 years hydrogel technology has come in to view as a new prevalent technology which may be going to discover more applications in different fields of research[1]. Hydrogels have evolved with inherent advantages beyond continuing technologies like diffusion and adsorption[2]. Due to industrial evolution and population expansion, need for more drinkable water as well as other sustainable materials from natural resources including gums and natural biomass has become an important issue[3-8]. The inattentive behavior of humans towards environment has majorly affected the condition of water by contaminating it with inadequate quantities of pesticides, drugs, dyes and other pollutants[9-13]. Hydrogels may act as new emerging technology that is being researched for water remediation[14]. Self-assembly of molecules is considered as the unique property, which is essential for the emergence or advancement of any material and hydrogel also show self-assembling nature in water[15]. Hydrogels exhibit most fragile three dimensional structure, soft nature, high water soaking capacity and porosity which makes it extremely suitable for loading water soluble bodies[16]. Furthermore, hydrogels are the biodegradable gels with interconnecting pores which play essential role in adsorption process and for confining more aquatic pollutants[3, 9], its porosity can be permanently achieved by following modifications: (a) by cryogelation[17], (b) integrating nanoparticles[4, 18], (c) by lyphilization (drying-freeze of swollen hydrogel)[17], (d) by grafting mechanism[19-21] and (e) by cross-linking polymerization[22]. Natural hydrogels can be replaced by artificial hydrogels having long life, high adsorption capacity, more mechanical strength and high swelling nature[23]. Herein, this review article, we have focused on guar gum derived hydrogel composites for waste water treatment. The structure and properties of gaur gum and composites have also been discussed in this article. 


\section{Guar gum}

A drought resistant plant named Cyamopsis tetragonoloba belongs to family leguminosae is an important agrochemical, derived from the endospermic part of guar seed mostly cultivated in Pakistan and India from ancient time is now becoming useful for many purposes[24]. It is a source of guar gum or guaran. Before 1940, guar gum has been reviewed in a limited extend[25]. It has achieved popularity in the field of science roughly around 1940s and 1950s and was used as industrial product in 1943[26]. Guar gum has strong hydrogen bonding tendency in water, that's why it acts as best thickener and stabilizing agent in various chemical processes. The use of this gum has increased tremendously in last few years specially in cosmetics, oils, paints, as adjunct in paper making, emulsifier, suspending and wound-healing agent[25]. The yellowish-white, natural, non-ionic and unprocessed guaran is a reserved part of the cluster bean which is essential for the germination of seed. On coming in contact with water like alginic acid, its inter-molecular chain creates a strong bond with surrounding hydroxyl groups which is necessary for attaining maximum viscosity potential in cold water[27]. Cluster bean is not considerably influenced by the $\mathrm{pH}$, but at $3.5 \mathrm{pH}$ it exhibits low viscosity potential and in between 6-9 it shows maximum viscosity potential that means over a broad $\mathrm{pH}$ range it resist with unchanging viscosity rate[28]. The development of gum derivatives is often necessary for fulfilling specific application requirements, derivatization of the unprocessed or virgin gum escort the desired and modified properties of the gum without ignoring inherent values up to the mark[29]. No doubt, chemical modifications like grafting, crosslinking, etherification and carboxylation makes it suitable for elevating potential applications in various fields of science but sidewise care should be taken to remove its inborn deficiencies so that we can use it for long term applications[30][31]. A raw structure with high molecular weight can be tailored to obtain desired range of properties for making it suitable for the certain applications. 
A number of derivatizations have been made on guar gum to elaborate its use in various fields like food industry[32], explosives[33], flocculating agent[34][35][36], agriculture[37], pollutant removing agent[38][39][40][41], paper industry[42], cosmetics[43], drug delivery[44] and in pharmaceuticals[45].

\section{Structural compositions of guar gum}

Guar gum is a natural non-ionic polysaccharide having high molecular weight drawn out from the endosperm portion of seed which basically consist of straight chain of D-mannose subunits united by $\beta$ (1-4) glycosidic bond and D-galactose subunits linked together by (1-6) glycosidic bond at each alternate positions[46]. The endosperm layer of guar kernel predominates the presence of galactose and mannose sub-unites which are collectively called as galactomannan units[47]. The ratio of galactose to mannose units has been reported as 1:2 and in range of 1:1.6 to $1: 1.8[48]$. Figure 1 shows the enlarged structure of endosperm wherein subunits are linked together at different positions to form a large polymeric chain. The core network of guar gum resembles like other polysaccharide gums but its elemental composition includes complex galactomannan units (75-85\%), 8-14\% of moisture content, $5-6 \%$ of protein, $2-3 \%$ of fibers and $0.5-1.0 \%$ of ash[46].

\section{Physical and chemical properties of guar gum}

The properties like swelling, solubility and hydrogen bonding making tendency are maximum in polar solvents rather than non-polar. Herein this review, we have tried to study all physical and chemical nature of the gum like dissolution, rheology, effect of $\mathrm{pH}$ and temperature, viscosity and most important one hydration rate which can be reduced by adding certain salts and binding sugars like sucrose [49]. 


\section{Viscosity}

It is a state of being thick, which depends upon percentage hydration of guar gum in cold water[50]. Guar gum is commonly thixotropic in nature because, on continuous stirring its gels come in liquid form. Moreover, high thixotropic behavior can be seen in case of more than $1 \%$ of guar gum in aqueous solution[51]. Its viscosity equally depends upon temperature, pressure, $\mathrm{pH}$ and amount of continuous agitation during synthesis[28].

\section{Rheology study}

Rheology gives the idea of deformation and flow of the viscous fluids when any external stress is applied. Guar gum exhibits pseudo plastic behavior which in rheology called as non-Newtonian behavior of gels[52]. According to shear-strain theory, viscosity of fluids undergo reduction with increase in shear-strain and this theory confirms the shear-thinning behavior of the different polymeric gels[53].

\section{Strong hydration rate}

Hydration is a physical phenomenon in which gum creates the cementing bonding with the water molecules[54]. Hydration rate dynamically depends upon time and size of the gum particles[33]. Rate of hydration increases with small particle size that means very fine powder of guar gum is required for getting quick viscosity at initial stage[55].

\section{Strong hydrogen bonding}

Strong hydrogen bonding in guar gum is because of the presence of hydroxyl groups[29]. For hydrogen bonding, a strong electronegative atom with heteronuclear dipole moment is required to complete dipole-dipole and attractive electrostatic interactions[56]. Guar gum shows strong 
bonding with hydrated molecules and cellulose derivatives. Importantly, the stability of bonds decreases by steric hindrance caused due to substitution of - $\mathrm{OH}$ groups of gum by hydroxypropyl groups[57].

\section{Effect of temperature}

Temperature equally affects the hydration rate and viscosity of the fluids. Guar gels attain higher viscosity at high temperature but long term heating may also cause degradative effect. They also show high rate of hydration in warm water whereas cold water permits the gum to hydrate slowly[58]. The reported temperature for attaining maximum viscosity is about $25-40^{\circ} \mathrm{C}$ wherever for $0.5 \%$ guar solution, $25^{\circ} \mathrm{C}$ temperature gives higher viscosity than the temperature of $37^{\circ} \mathrm{C}$ and at constant temperature, $0.5 \%$ gum solution behaves as Newtonian system[59].

\section{Effect of pH}

Because of uncharged and non-ionic behavior, guar gum exhibits stable properties for wide range of $\mathrm{pH}$. Different $\mathrm{pH}$ solutions do not affect the final viscosity but it may affect the hydration rate, and fastest hydration rate can be found at $\mathrm{pH} 8$ which may drop at more than $\mathrm{pH} 10$ or less than 4[60]. Considerably, maximum adsorption for various pollutant is shown by the guar gum based hydrogels at $\mathrm{pH} 10[61]$.

\section{Effect of concentration}

High viscosity is essential for fulfilling food applications and guar gum forms deep thick solution at low concentration[62]. Viscosity is just proportional to the concentration and size of the gum particles and this is because of water and galactose chain interaction. Increase in these side chain interactions entangles the more viscous behavior of gum solution[63]. 


\section{Guar gum based hydrogels for water purification}

One of the possible mechanisms followed in water purification is adsorption. For this, numbers of fillers and chemical modifications have been investigated to achieve required application in water remediation program[64],[65], [66], [67], [68], [69], [70],[71],[72]. Table 1 shows different types of modified guar gum based hydrogels adsorbents material for water pollutants removal. Hydrogels based on guar gum-polyacrylamide (GG-Poly-AAm) and modified guar gumpolyacrylamide m-(GG-Poly-AAm) were used for evaluating removal percentage of azure B and crystal violet dyes[65]. Methylene bis-acrylamide and glutaraldehyde were used as cross-linkers for getting well linked network. In this work, saponification of prepared hydrogel was performed in strong basic media to improve compatibility for dye sorption. Moreover, alkaline hydrolysis of m-(GG-Poly-AAm) led to the generation of carboxylic groups which enhanced the anionic moiety of the hydrogel network.

The differential scanning calorimetry (DSC) pattern of GG-Poly-AAm (neutralization equivalent $(\mathrm{NE})=0), \mathrm{m}-\mathrm{GG}-\mathrm{Poly}-\mathrm{AAm} 1(\mathrm{NE}=426.2), \mathrm{m}-\mathrm{GG}-\mathrm{Poly}-\mathrm{AAm} 2(\mathrm{NE}=294.4)$ and m-GG-PolyAAm3 (NE=222.0) were investigated. The melting transition peak for GG-Poly-AAm was spotted at $273{ }^{\circ} \mathrm{C}$, which was slowly diminished in m-GG-PolyAAm because of formation of carboxylic groups from amide functionality and totally disappeared in m-GG-Poly-AAm3 which again assured the formation of more $-\mathrm{COOH}$ groups inside the gel. TGA analyses showed the mass loss of the samples which was about $5 \%$ at starting and then increased to $30-35 \%$ at $230-350{ }^{\circ} \mathrm{C}$ assigned to the loss of $-\mathrm{OH}$ groups of guar gum. The hygroscopic nature of m-GG-Poly-AAm samples was confirmed by higher mass loss percentage at initial stage which was then equivalent to the GG-Poly-AAm gel at intermediate stage. Kinetic study displayed that system followed the 
second order kinetics and thermodynamic evaluation supported the exothermic adsorption of dyes on mGG-Poly-AAm2 surface.

Methylene blue dye was removed by Sharma et al. using polyaniline based guar gum/acrylic acid hydrogel[66]. They synthesized guar gum cross-linked polyacrylic acid (GG-cl-Poly(AA)) hydrogel by solvent evaporation which was further used for the preparation of guar gum crosslinked polyacrylic acid with interpenetrating network of polyaniline (GG-cl-Poly(AA-ipn-aniline). Similar method was followed in acidic conditions where GG-cl-Poly (AA-ipn-aniline) hydrogel was treated with $0.5 \mathrm{~N}$ solution of $\mathrm{HCl}$ to form doped-GG-cl-Poly (AA-ipn-aniline) hydrogel. Molecules of methylene dye were separated from different gel mixtures, their dye uptake efficiency was investigated in detail. It was mentioned that percentage removal for dye may vary with different parameters. With passage of time, methylene blue percentage removal was increased to $52.98 \%, 54.68 \%$ and $61.83 \%$ for doped-GG-cl-Poly (AA-ipn-aniline), undoped-GG-cl-Poly (AA-ipn-aniline) and GG-cl-Poly (AA) hydrogels respectively (Figure 2a). Figure 2b shows that dose of $300 \mathrm{mg}$ was optimized for maximum removal percentages of $64.4 \%, 56.4 \%$ and $54.9 \%$ for GG-cl-Poly (AA), undoped-GG-cl-Poly (AA-ipn-aniline) and doped-GG-cl-Poly (AA-ipnaniline) hydrogels respectively. The maximum methylene blue adsorption was found at $\mathrm{pH} 10$, dye adsorption was higher at high $\mathrm{pH}$, poor adsorption at low $\mathrm{pH}$ because of high repulsive electrostatic interactions between dye and hydrogel samples (Figure 2c). The high temperature conditions were resulted in increased porosity and swelling, hence adsorption was enhanced with temperature (Figure 2d). At $70^{\circ} \mathrm{C}$, adsorption efficiency was $69.15 \%$ for GG-cl-Poly (AA) hydrogel whereas undoped and doped hydrogel samples exhibited the efficiency of $64.22 \%$ and62.60\% respectively. The rough surface of cross linked hydrogels (Figure 3b-d) was observed 
in comparison to smooth surface of pure guar gum (Figure 3a). The roughness of doped hydrogel surface was more intense than undoped hydrogel surface.

Thombare et al. developed hydrogel of guar gum cross linked with borax (GG-cl-B) at different concentrations[67]. The developed hydrogel was applied for the adsorption of aniline blue (AB) dye from water. The synthesis of GG-cl-B is clearly represented in Figure 4, where boron was believed to make bond with different oxygen atoms of hydroxyl groups[73].

Distinct flake like morphology (Figure 5a) and a compact smooth surface (Figure 5b) was reported for pure gum powder and guar gum film respectively[74]. But for GG-cl-B hydrogel, an extraordinary change was observed, the surface morphology changed to porous scaly structure which attributes more fluid diffusion (Figure 5c). Guar gum represented three different weight loss zones of $25-270{ }^{\circ} \mathrm{C}, 270-330{ }^{\circ} \mathrm{C}$ and $330-562^{\circ} \mathrm{C}$ whereas GG-cl-B hydrogel showed four different weight loss zones of $25-280{ }^{\circ} \mathrm{C}, 280-330{ }^{\circ} \mathrm{C}, 330-508^{\circ} \mathrm{C}$ and $508-600{ }^{\circ} \mathrm{C}$. Both samples showed maximum weight loss in second zone which were nearly about $54 \%$ and $34 \%$ for guar gum and GG-cl-B hydrogel respectively.

Variety of modifications has been done for the removal of heavy metal ions. Among all, grafting and integration of nanoparticles are considered as best techniques for developing best adsorbent material[68]. A low cost guar gum was used as a backbone for making novel hydrogel adsorbent material for sorption of $\mathrm{Cr}$ (VI) metal ion from water. The incorporation of bentonite nanoclay increased the mechanical strength and hydrophilicity of the prepared composite hydrogel. This hydrogel composite had achieved the removal percentage of $97.8 \%$ at $\mathrm{pH} 2.0$.

Figure 6a shows the stepwise synthesis of guar gum/bentonite hydrogel composite (CPGB) started with free radical generation from initiator (potassium peroxydisulfate), followed with generation of monomers and gum radicals with the addition of $\mathrm{N}, \mathrm{N}$-methylenebis acrylamide as cross linker. 
Finally, polymerization with bentonite nanoparticles was carried out to produce guar gum/bentonite hydrogel composite. Figure $\mathbf{6 b}$ represents the repeated evaluation of swellability and de-swellability of hydrogels at $\mathrm{pH}$ of 2.0 and 8.0. This study confirmed the good reversibility of hydrogels after 3 to 4 cycles of high and low $\mathrm{pH}$ and best mechanical strength was shown by the bentonite incorporated guar gum composite hydrogel (CPGB4) $($ guar gum $=1 \mathrm{wt} \%$, bentonite $=2 \mathrm{wt} \%$ and monomer ratio (acrylic acid: hydroxyethyl methacrylate) $=10: 1$ ) than copolymer hydrogel $(\mathrm{CP} 4)$ (guar gum $=0 \mathrm{wt} \%$, bentonite $=0 \mathrm{wt} \%$ and monomer ratio (acrylic acid: hydroxyethyl methacrylate) $=10: 1$ ) and guar gum incorporated copolymer gel (CPG4) (guar gum $=5 \mathrm{wt} \%$, bentonite $=0 \mathrm{wt} \%$ and monomer ratio (acrylic acid: hydroxyethyl methacrylate) $=$ 10:1).Importantly, there was a loss in crystal behavior of guar gum and clay particles because of the attractive and repulsive interactions residing in between the functional groups of the gum and bentonite clay particles presented inside the polymeric gel (water + guar gum).

In another work, grafting of acrylamide was carried out to synthesize guar gum based hydrogel for the removal of hexavalent chromium ion [70]. The polymerization technique was used for the grafting of acrylamide onto the guar gum using redox system of potassium bromate and thiourea dioxide. In final step, prepared guar gum based polyacrylamide grafted polymer was cross-linked with glutaraldehyde to produce the hydrogel. The prepared guar gum grafted polyacrylamide hydrogel was utilized for the removal of chromium hexavalent ion with maximum adsorption capacity of $588.24 \mathrm{mg} \mathrm{g}^{-1}$.

The synthesis of guar gum based polyacrylamide grafted copolymer is shown in the Figure 7a. The prepared guar gum based polyacrylamide grafted copolymer was further cross linked with glutaraldehyde for the formation of cross-linked hydrogel as represented in the Figure $\mathbf{7 b}$. Furthermore, sorption study revealed that amount of adsorbed $\mathrm{Cr}(\mathrm{VI})$ ion depends upon the extent 
of grafting in prepared hydrogel (Figure 7c). A novel guar gum based hydrogel was synthesized by Chauhan et al. for the sorption of $\mathrm{Cu}$ (II) ions using clean and effective acid hydrolysis[71]. Depolymerized guar gum and domestic guar gum were oxidized with the help of nitrogen oxide $\mathrm{NO}_{\mathrm{x}}$ (oxidant) and then samples were cross-linked with $\mathrm{N}, \mathrm{N}$-methylene bisacrylamide. Maximum adsorption capacity of $125.893 \mathrm{mg} \mathrm{g}^{-1}$ was reported after 2 hours at $40^{\circ} \mathrm{C}$ using $20 \mathrm{ppm}$ of Cu (II) solution.

\section{Conclusions}

In this article, we have tried to explore structure, chemical and physical aspects of guar gum with prime focus on its application as pollutant removing agent in water purification. It is a natural, harmless, renewable, low cost, highly viscous and $\mathrm{pH}$ compatible polysaccharide which may easily blend into supportable products. All these properties of guar gum provide an edge to other similar derivatives of this field. Guar gum is now being considered as one of the most promising potential candidate to explore better outcomes in possible adsorption techniques and can act as preferred choice for different areas of research interests.

\section{Acknowledgement}

Sourbh Thakur acknowledges financial support by Postdoctoral Fellowship project No 09.3.3LMT-K-712-02-0180 of Measure 09.3.3-LMT-K-712 'Development of Scientific Competences of Scientists, other Researchers and Students through Practical Research Activities' (Funding instrument - European Social Fund). Sourbh Thakur is also thankful to Kaunas University of Technology. 


\section{References}

1. Thakur VK, Voicu SI (2016) Recent advances in cellulose and chitosan based membranes for water purification: a concise review. Carbohydr Polym 146:148-165

2. Thakur VK, Thakur MK (2015) Recent advances in green hydrogels from lignin: a review. Int J Biol Macromol 72:834-847

3. Thakur S, Govender PP, Mamo MA, et al (2017) Recent progress in gelatin hydrogel nanocomposites for water purification and beyond. Vacuum 146:396-408

4. Thakur S, Arotiba O (2018) Synthesis, characterization and adsorption studies of an acrylic acid-grafted sodium alginate-based $\mathrm{TiO} 2$ hydrogel nanocomposite. Adsorpt Sci Technol $36: 458-477$

5. Thakur S, Pandey S, Arotiba OA (2017) Sol-gel derived xanthan gum/silica nanocomposite - a highly efficient cationic dyes adsorbent in aqueous system. Int J Biol Macromol 103:596-604

6. Singha AS, Thakur VK (2009) Synthesis, Characterisation and Analysis of Hibiscus Sabdariffa Fibre Reinforced Polymer Matrix Based Composites. Polym Polym Compos 17:189-194

7. Thakur VK, Singha AS, Thakur MK (2013) Fabrication and Physico-Chemical Properties of High-Performance Pine Needles/Green Polymer Composites. Int J Polym Mater Polym Biomater 62:226-230 . doi: 10.1080/00914037.2011.641694

8. Singha AS, Thakur VK (2008) Fabrication of Hibiscus sabdariffa fibre reinforced polymer composites. Iran Polym J 17:541-553

9. Thakur S, Govender PP, Mamo MA, et al (2017) Progress in lignin hydrogels and nanocomposites for water purification: Future perspectives. Vacuum 146:342-355

10. Thakur S, Chaudhary J, Sharma B, et al (2018) Sustainability of Bioplastics: Opportunities and Challenges. Curr Opin Green Sustain Chem 
11. Thakur S, Verma A, Sharma B, et al (2018) Recent developments in recycling of polystyrene based plastics. Curr Opin Green Sustain Chem

12. Thakur S, Arotiba OA Synthesis, swelling and adsorption studies of a $\mathrm{pH}$-responsive sodium alginate-poly (acrylic acid) superabsorbent hydrogel. Polym Bull 1-20

13. Madhumitha G, Fowsiya J, Roopan SM, Thakur VK (2018) Recent advances in starch-clay nanocomposites. Int J Polym Anal Charact 23:331-345 . doi:

10.1080/1023666X.2018.1447260

14. Patra AS, Ghorai S, Sarkar D, et al (2017) Anionically functionalized guar gum embedded with silica nanoparticles: An efficient nanocomposite adsorbent for rapid adsorptive removal of toxic cationic dyes and metal ions. Bioresour Technol 225:367-376

15. Du X, Zhou J, Shi J, Xu B (2015) Supramolecular hydrogelators and hydrogels: from soft matter to molecular biomaterials. Chem Rev 115:13165-13307

16. Thakur VK, Thakur MK, Raghavan P, Kessler MR (2014) Progress in green polymer composites from lignin for multifunctional applications: a review. ACS Sustain Chem Eng 2:1072-1092

17. Pradny M, Vetrik M, Hruby M, Michalek J (2014) Biodegradable Porous Hydrogels. Adv Healthc Mater 269-293

18. Trache D, Hazwan Hussin M, Mohamad Haafiz MK, Kumar Thakur V (2017) Recent progress in cellulose nanocrystals: sources and production. Nanoscale 9:1763-1786 . doi: 10.1039/C6NR09494E

19. Tally M, Atassi Y (2016) Synthesis and characterization of pH-sensitive superabsorbent hydrogels based on sodium alginate-g-poly (acrylic acid-co-acrylamide) obtained via an anionic surfactant micelle templating under microwave irradiation. Polym Bull 73:31833208 
20. Thakur MK, Thakur VK, Gupta RK, Pappu A (2016) Synthesis and Applications of Biodegradable Soy Based Graft Copolymers: A Review. ACS Sustain Chem Eng 4:1-17 . doi: 10.1021/acssuschemeng.5b01327

21. Thakur VK, Thakur MK, Gupta RK (2013) Synthesis of lignocellulosic polymer with improved chemical resistance through free radical polymerization. Int J Biol Macromol 61:121-126 . doi: 10.1016/j.ijbiomac.2013.06.045

22. Ngah WW, Teong LC, Hanafiah M (2011) Adsorption of dyes and heavy metal ions by chitosan composites: A review. Carbohydr Polym 83:1446-1456

23. Güven O, Şen M, Karadağ E, Saraydın D (1999) A review on the radiation synthesis of copolymeric hydrogels for adsorption and separation purposes1. Radiat Phys Chem $56: 381-386$

24. Yogi RK, Bhattacharya A, Jaiswal AK, Alok K (2015) Lac, plant resins and gums statistics 2014: at a glance. ICAR-Indian Institute of Natural Resins and Gums, Namkum, Ranchi

25. Thombare N, Jha U, Mishra S, Siddiqui MZ (2016) Guar gum as a promising starting material for diverse applications: A review. Int J Biol Macromol 88:361-372

26. Coale AJ, Hoover EM (2015) Population growth and economic development. Princeton University Press

27. Parija S, Misra M, Mohanty AK (2001) Studies of natural gum adhesive extracts: an overview. J Macromol Sci Part C Polym Rev 41:175-197

28. Zhang L-M, Zhou J-F, Hui PS (2005) A comparative study on viscosity behavior of watersoluble chemically modified guar gum derivatives with different functional lateral groups. J Sci Food Agric 85:2638-2644

29. Thombare N, Jha U, Mishra S, Siddiqui MZ (2016) Guar gum as a promising starting material for diverse applications: A review. Int J Biol Macromol 88:361-372 
30. Sullad AG, Manjeshwar LS, Aminabhavi TM (2010) Novel pH-sensitive hydrogels prepared from the blends of poly (vinyl alcohol) with acrylic acid-graft-guar gum matrixes for isoniazid delivery. Ind Eng Chem Res 49:7323-7329

31. Gupta AP, Verma DK (2014) Guar gum and their derivatives: a research profile. Int J Adv Res 2:680-690

32. Saha A, Tyagi S, Gupta RK, Tyagi YK (2017) Natural gums of plant origin as edible coatings for food industry applications. Crit Rev Biotechnol 37:959-973

33. Mudgil D, Barak S, Khatkar BS (2014) Guar gum: processing, properties and food applications-a review. J Food Sci Technol 51:409-418

34. Dai L, Wang B, An X, et al (2017) Oil/water interfaces of guar gum-based biopolymer hydrogels and application to their separation. Carbohydr Polym 169:9-15

35. Nayak BR, Singh RP (2001) Development of graft copolymer flocculating agents based on hydroxypropyl guar gum and acrylamide. J Appl Polym Sci 81:1776-1785

36. Singh RP, Pal S, Mal D (2006) A high performance flocculating agent and viscosifiers based on cationic guar gum. In: Macromolecular symposia. Wiley Online Library, pp 227234

37. Thombare N, Mishra S, Siddiqui MZ, et al (2018) Design and development of guar gum based novel, superabsorbent and moisture retaining hydrogels for agricultural applications. Carbohydr Polym

38. Pathania D, Katwal R, Sharma G, et al (2016) Novel guar gum/A12O3 nanocomposite as an effective photocatalyst for the degradation of malachite green dye. Int J Biol Macromol $87: 366-374$

39. Pal S, Patra AS, Ghorai S, et al (2015) Efficient and rapid adsorption characteristics of templating modified guar gum and silica nanocomposite toward removal of toxic reactive blue and Congo red dyes. Bioresour Technol 191:291-299 
40. Blackburn RS (2004) Natural polysaccharides and their interactions with dye molecules: applications in effluent treatment. Environ Sci Technol 38:4905-4909

41. Gupta VK, Pathania D, Singh P, et al (2014) Adsorptional removal of methylene blue by guar gum-cerium (IV) tungstate hybrid cationic exchanger. Carbohydr Polym 101:684-691

42. Wang Y, Xu Q-H (2017) Quaternary ammonium cationic tara gum and its application in papermaking. In: Advanced Materials and Energy Sustainability: Proceedings of the 2016 International Conference on Advanced Materials and Energy Sustainability (AMES2016). World Scientific, pp 226-232

43. Kobayashi S, Oshimura E (2017) Cosmetic composition containing water-soluble moisturizing component and acyl basic amino acid derivative

44. Anirudhan TS, Nair SS (2017) Deposition of gold-cellulose hybrid nanofiller on a polyelectrolyte membrane constructed using guar gum and poly (vinyl alcohol) for transdermal drug delivery. J Membr Sci 539:344-357

45. Dziadkowiec J, Mansa R, Quintela A, et al (2017) Preparation, characterization and application in controlled release of Ibuprofen-loaded guar gum/Montmorillonite bionanocomposites. Appl Clay Sci 135:52-63

46. Tripathy S, Das MK (2013) Journal of Pharmaceutical and Scientific Innovation

47. Grasdalen H, Painter T (1980) NMR studies of composition and sequence in legume-seed galactomannans. Carbohydr Res 81:59-66

48. Garti N, Leser ME (2001) Emulsification properties of hydrocolloids. Polym Adv Technol $12: 123-135$

49. Whistler RL, BeMiller JN (1993) Industrial polysaccharides and their uses. Acad Press San Diego CA

50. Bai L, Liu F, Xu X, et al (2017) Impact of polysaccharide molecular characteristics on viscosity enhancement and depletion flocculation. J Food Eng 207:35-45 
51. Wang T, Zhang M, Fang Z, et al (2016) Rheological, textural and flavour properties of yellow mustard sauce as affected by modified starch, xanthan and guar gum. Food Bioprocess Technol 9:849-858

52. Tantry JS, Mangal NS (2001) Rheological study of guar gum. Indian J Pharm Sci 63:74

53. Achayuthakan P, Suphantharika M (2008) Pasting and rheological properties of waxy corn starch as affected by guar gum and xanthan gum. Carbohydr Polym 71:9-17

54. Ellis PR, Morris ER (1991) Importance of the rate of hydration of pharmaceutical preparations of guar gum; a new in vitro monitoring method. Diabet Med 8:378-381

55. Schierbaum F (1971) Glicksman, M.: Gum Technology in the Food Industry, Academic Press, New York and London, 1969. XIII, 590 S., $8^{\circ}$, mit zahlreichen Abb. und Tab., Ganzleinen, Preis \$27, 50. Starch-Stärke 23:372-373

56. Christianson DD, Hodge JE, Osborne D, Detroy RW (1981) Gelatinization of wheat starch as modified by xanthan gum, guar gum, and cellulose gum. Cereal Chem 58:513-517

57. Cheng Y, Prud'Homme RK, Chik J, Rau DC (2002) Measurement of forces between galactomannan polymer chains: effect of hydrogen bonding. Macromolecules 35:1015510161

58. Sandolo C, Matricardi P, Alhaique F, Coviello T (2009) Effect of temperature and crosslinking density on rheology of chemical cross-linked guar gum at the gel point. Food Hydrocoll 23:210-220

59. Srichamroen A (2007) Influence of temperature and salt on viscosity property of guar gum. Naresuan Univ J Sci Technol 15:55-62

60. Wang S, Tang H, Guo J, Wang K (2016) Effect of pH on the rheological properties of borate crosslinked hydroxypropyl guar gum hydrogel and hydroxypropyl guar gum. Carbohydr Polym 147:455-463 
61. Patra AS, Ghorai S, Ghosh S, et al (2016) Selective removal of toxic anionic dyes using a novel nanocomposite derived from cationically modified guar gum and silica nanoparticles. J Hazard Mater 301:127-136

62. Yoon S-J, Chu D-C, Juneja LR (2008) Chemical and physical properties, safety and application of partially hydrolized guar gum as dietary fiber. J Clin Biochem Nutr 42:1-7

63. Whistler RL (1993) Introduction to industrial gums. In: Industrial Gums (Third Edition). Elsevier, pp 1-19

64. Sharma R, Kalia S, Kaith BS, Srivastava MK (2016) Synthesis of guar gum-acrylic acid graft copolymers based biodegradable adsorbents for cationic dye removal. Int J Plast Technol 20:294-314

65. Hiremath JN, Vishalakshi B (2015) Evaluation of a pH-responsive guar gum-based hydrogel as adsorbent for cationic dyes: kinetic and modelling study. Polym Bull 72:30633081

66. Sharma R, Kaith BS, Kalia S, et al (2015) Biodegradable and conducting hydrogels based on Guar gum polysaccharide for antibacterial and dye removal applications. J Environ Manage 162:37-45

67. Thombare N, Jha U, Mishra S, Siddiqui MZ (2017) Borax cross-linked guar gum hydrogels as potential adsorbents for water purification. Carbohydr Polym 168:274-281

68. Maity J, Ray SK (2016) Enhanced adsorption of Cr (VI) from water by guar gum based composite hydrogels. Int J Biol Macromol 89:246-255

69. Hiremath JN, Vishalakshi B (2016) Effective removal of divalent metal ions: synthesis and characterization of $\mathrm{pH}$-sensitive guar gum based hydrogels. Desalination Water Treat 57:4018-4027

70. Abdel-Halim ES, Al-Deyab SS (2011) Hydrogel from crosslinked polyacrylamide/guar gum graft copolymer for sorption of hexavalent chromium ion. Carbohydr Polym 86:13061312 
71. Chauhan K, Chauhan GS, Ahn J-H (2009) Synthesis and characterization of novel guar gum hydrogels and their use as $\mathrm{Cu} 2+$ sorbents. Bioresour Technol 100:3599-3603

72. Singh V, Pandey S, Singh SK, Sanghi R (2009) Removal of cadmium from aqueous solutions by adsorption using poly (acrylamide) modified guar gum-silica nanocomposites. Sep Purif Technol 67:251-261

73. Jafry HR, Pasquali M, Barron AR (2011) Effect of functionalized nanomaterials on the rheology of borate cross-linked guar gum. Ind Eng Chem Res 50:3259-3264

74. Chandrika KSV, Singh A, Sarkar DJ, et al (2014) pH-sensitive crosslinked guar gum-based superabsorbent hydrogels: Swelling response in simulated environments and water retention behavior in plant growth media. J Appl Polym Sci 131: 
Figures:

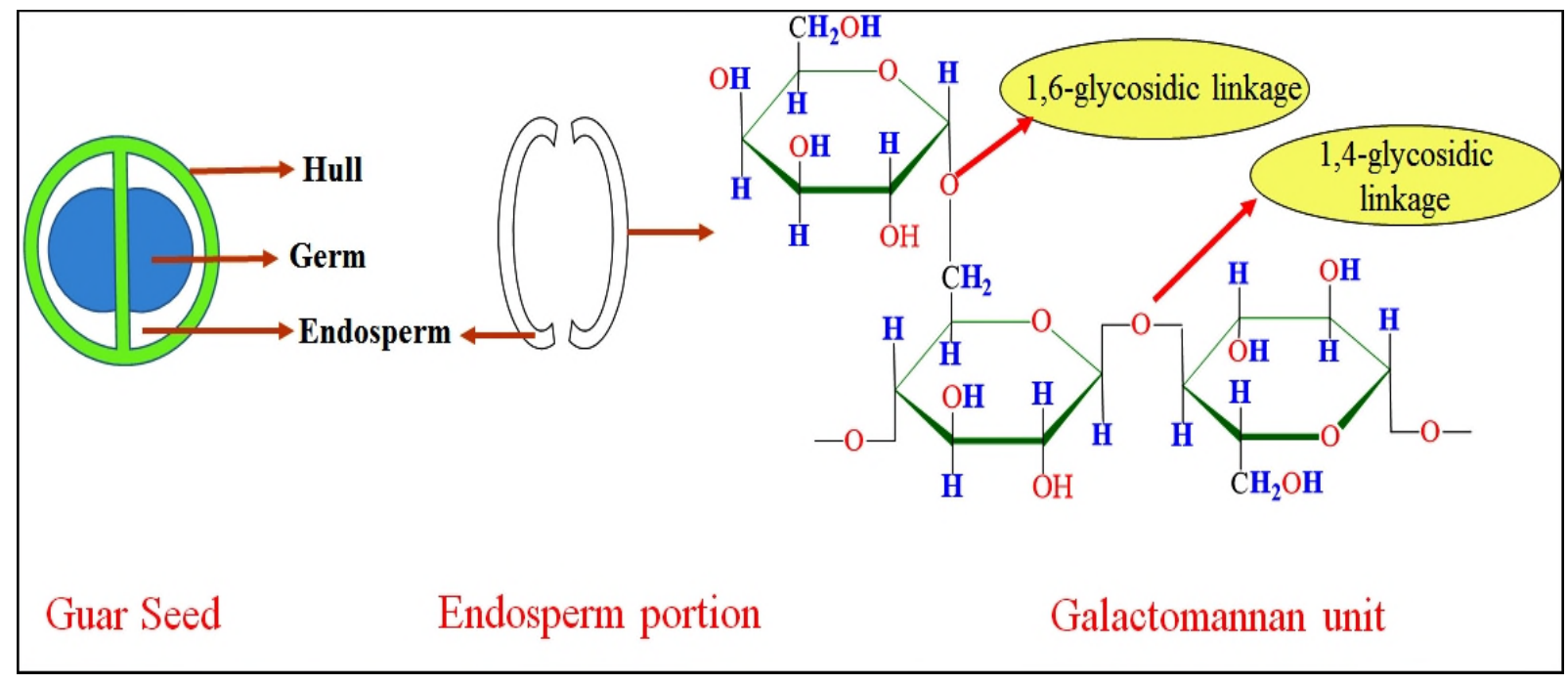

Figure 1. Showing endospermic part of guar seed which is made up of galactomannan units
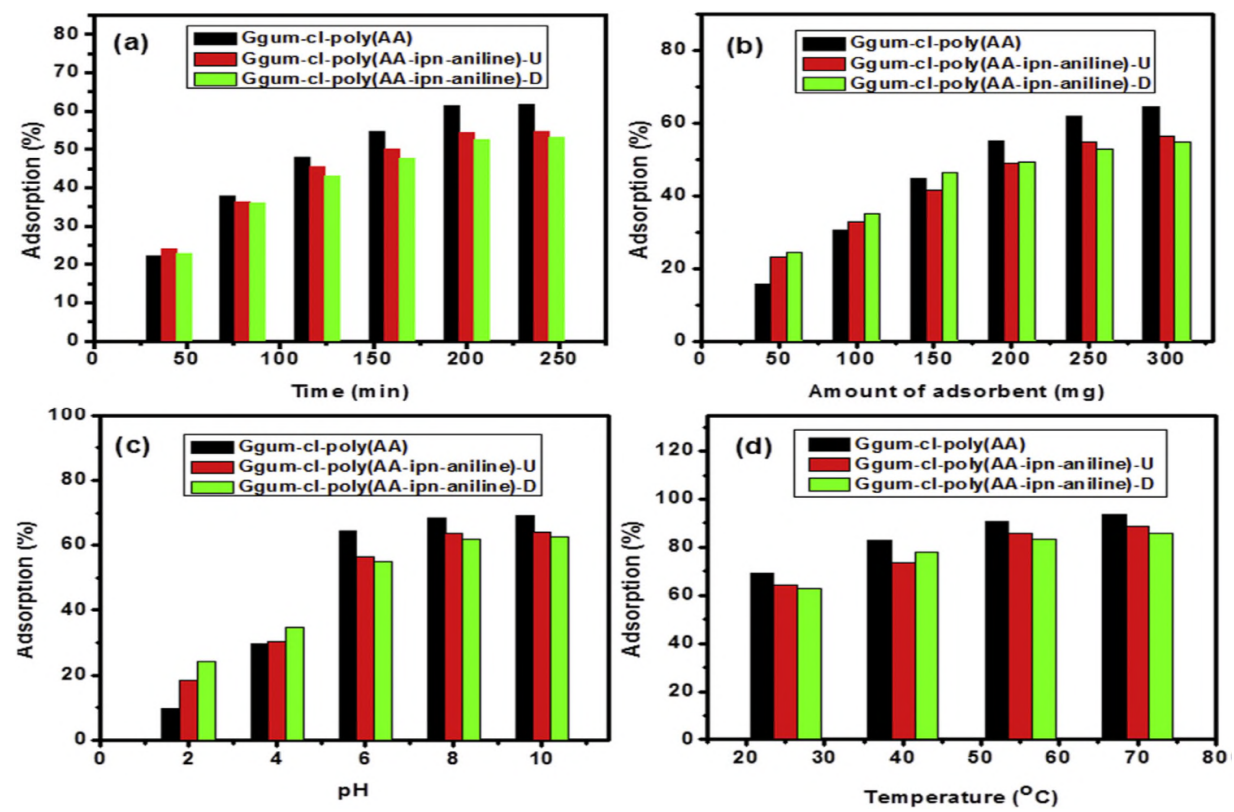

Figure 2. Different adsorption parameters explaining (a) effect of time, (b) effect of dose, (c) effect of $\mathrm{pH}$ and (d) effect of temperature [66]. Reprinted with permission from [66]. Copyright 2015 Elsevier. 


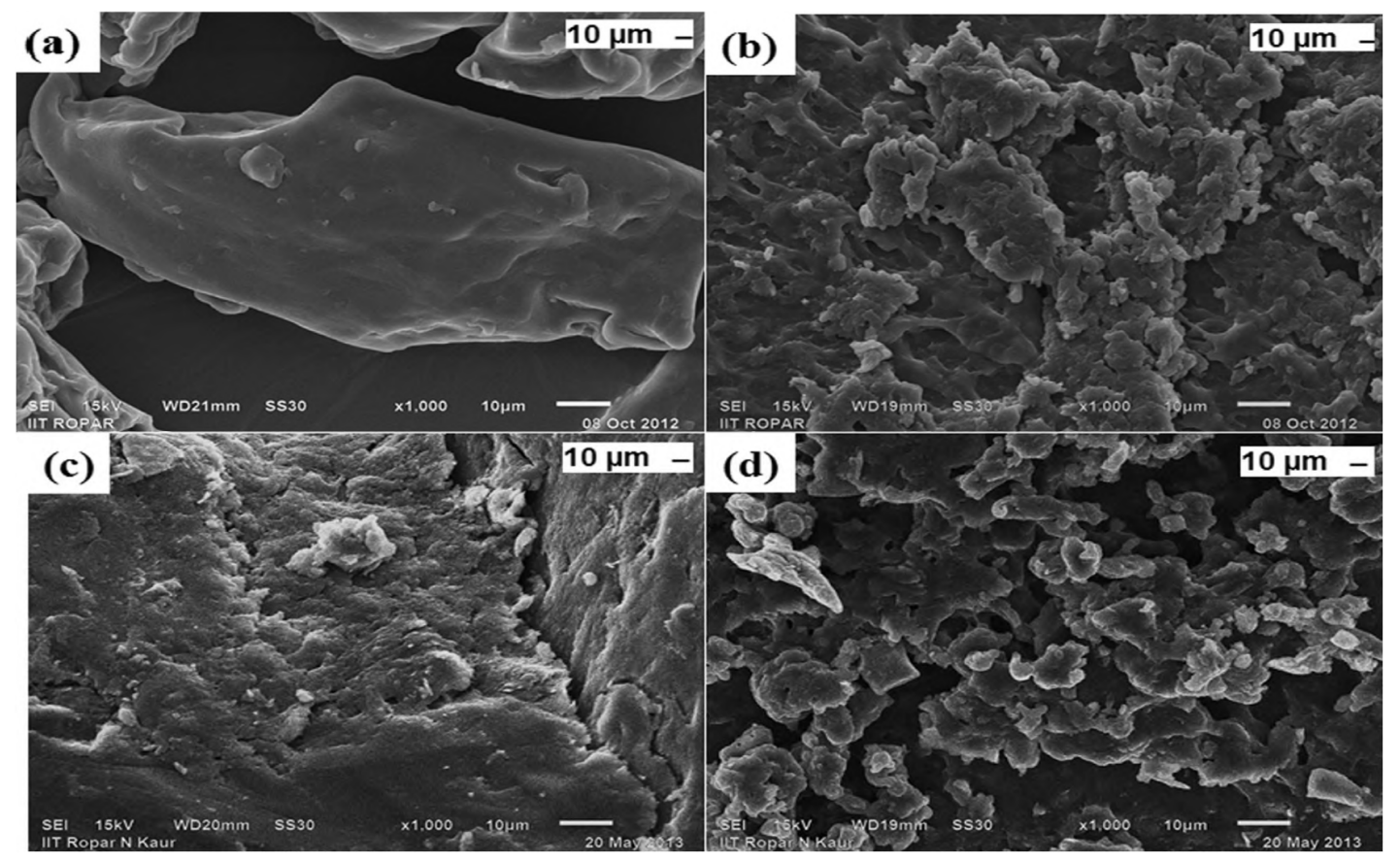

Figure 3. SEM images of (a) guar gum (b) GG-cl-Poly(AA) (c) undoped-GG-cl-Poly(AA-ipnaniline) (d) doped-GG-cl-Poly(AA-ipn-aniline) [66]. Reprinted with permission from [66]. Copyright 2015 Elsevier.

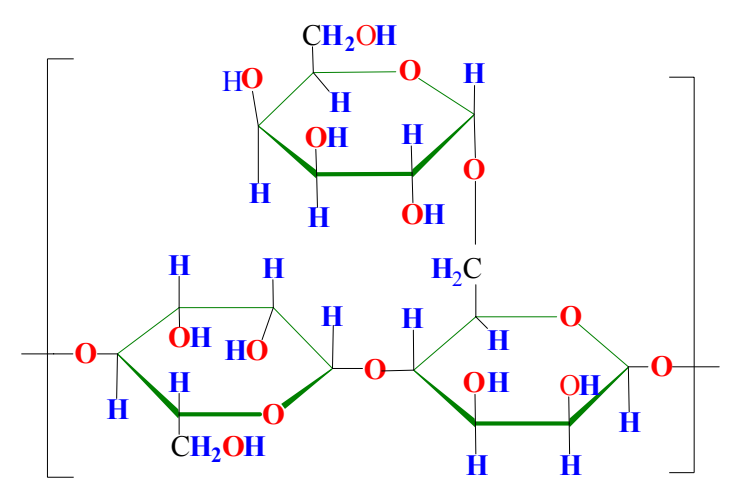

Guar Galactomannan

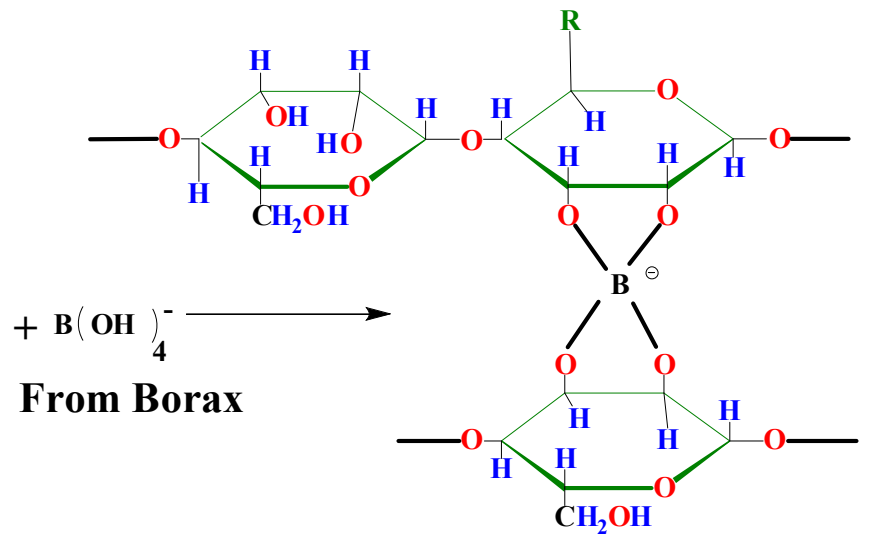

Guar-Borax Hydrogel

Figure 4. Schematic representation of synthesis of borax cross linked guar gum hydrogel (GG-clB)[67]. Reproduced with permission from [67]. Copyright 2017 Elsevier. 


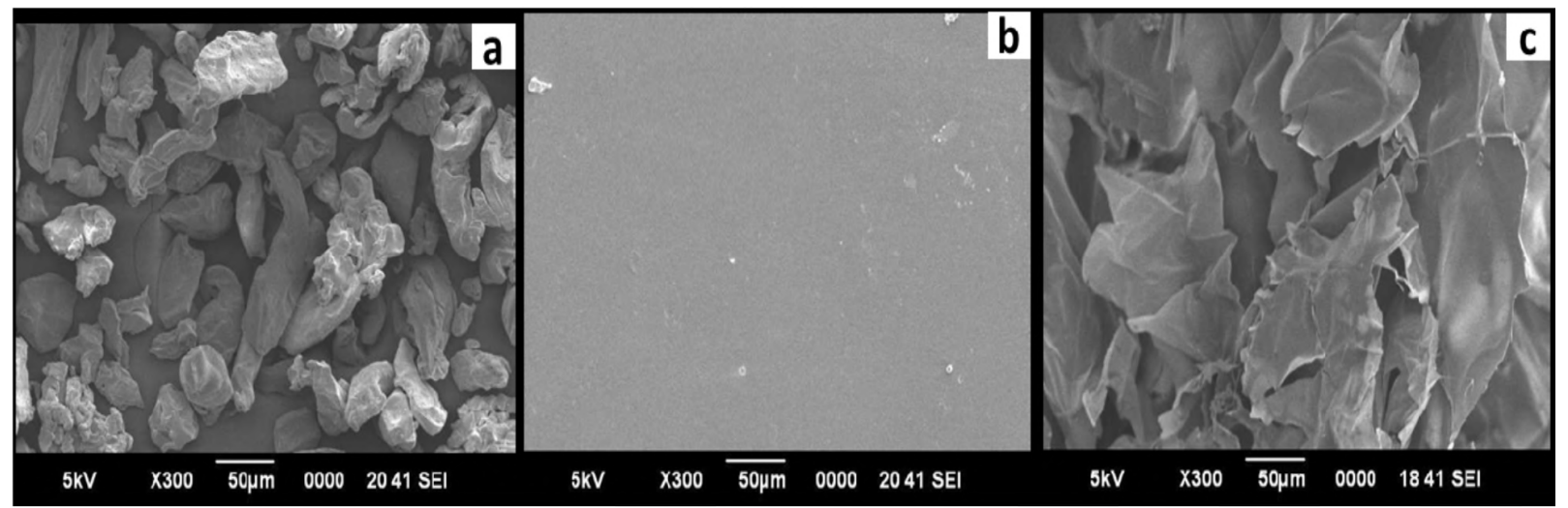

Figure 5. SEM images of (a) guar gum powder, (b) guar gum film, (c) GG-cl-B hydrogel[67]. Reprinted with permission from[67]. Copyright 2017 Elsevier. 
Step-I: Generation of free radical from initiator

$$
\mathrm{S}_{2} \mathrm{O}_{n^{2}} \triangle \mathrm{SO}_{4^{2}} \cdot(\mathrm{i})
$$

Step-II: Generation of guar gum macroradical and monomer radicals
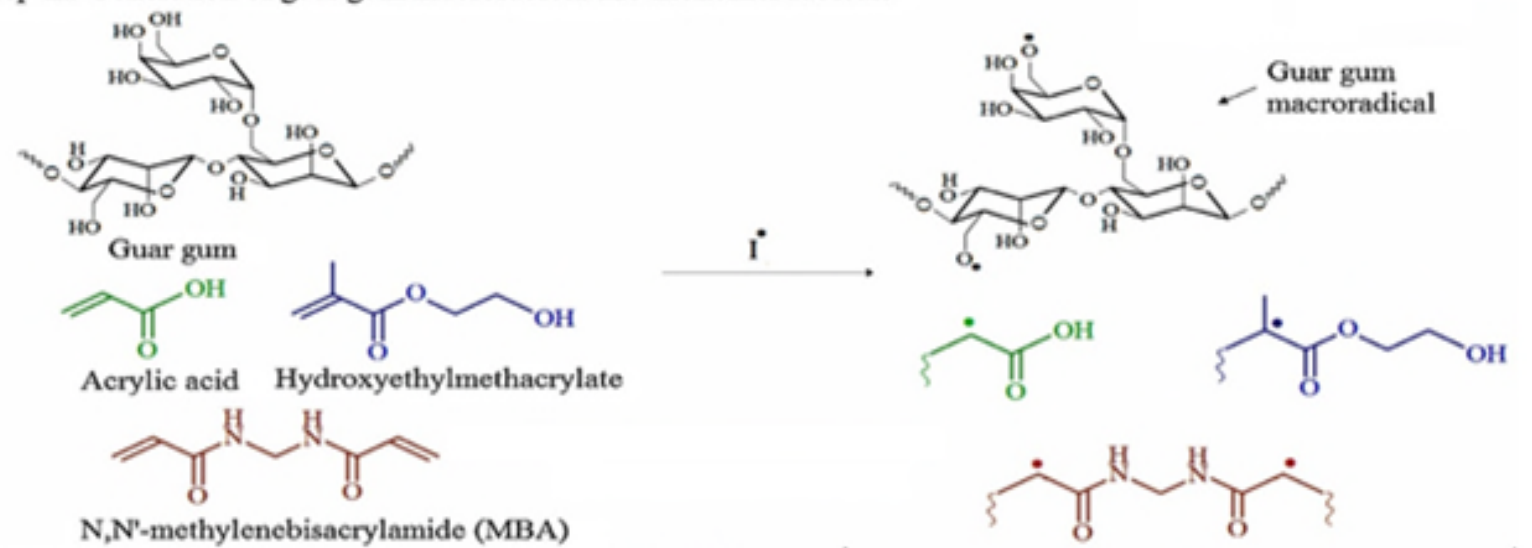

$\mathrm{N}, \mathrm{N}$-methylenebisacrylamide (MBA)

Step-III: Polymerisation in the presence of Bentonite clay
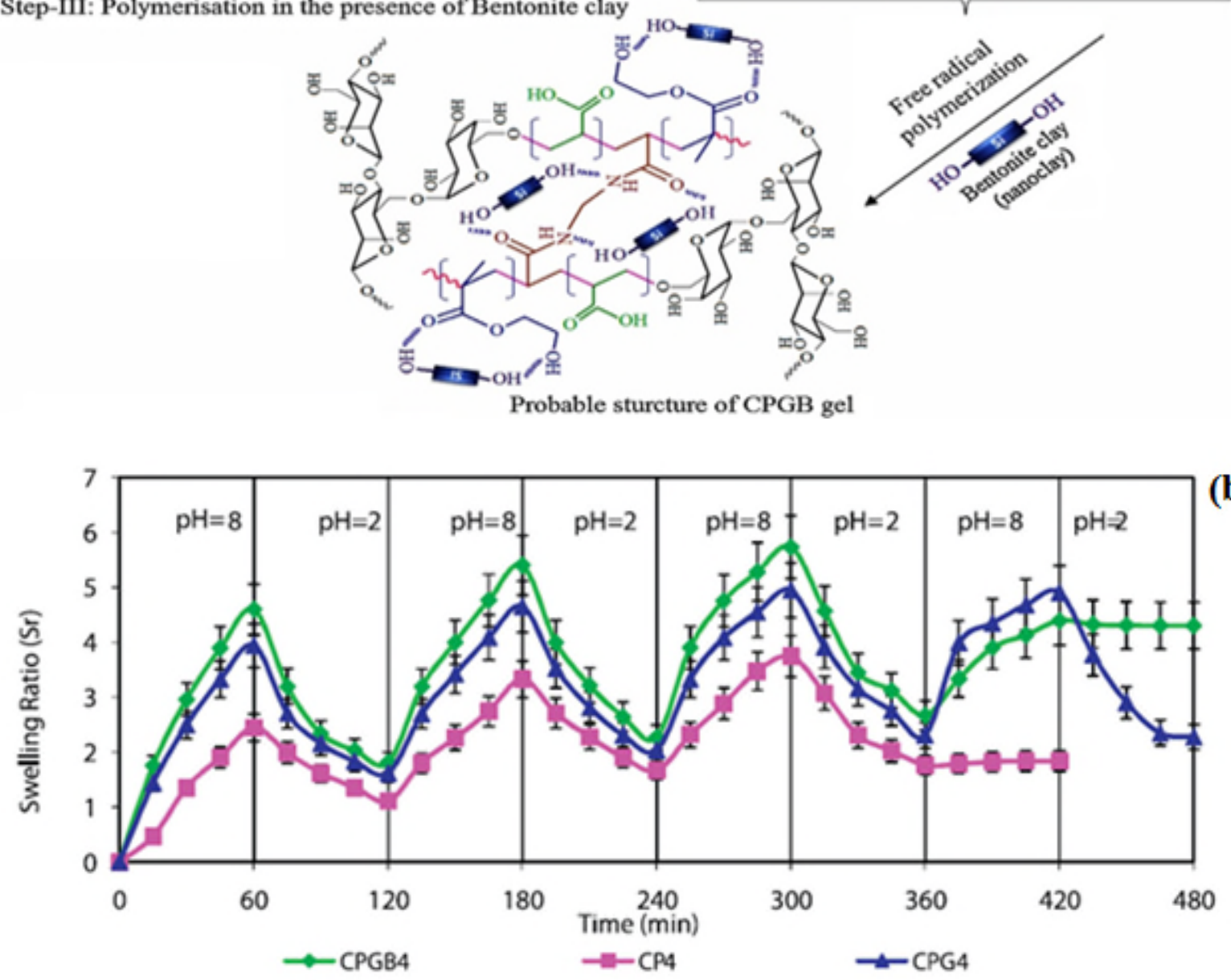

(b)

Figure 6. (a) Possible scheme for the synthesis of guar gum/bentonite composite hydrogel, (b) reversibility study of hydrogels with respect to time [68]. Reprinted with permission from [68]. Copyright 2016 Elsevier. 

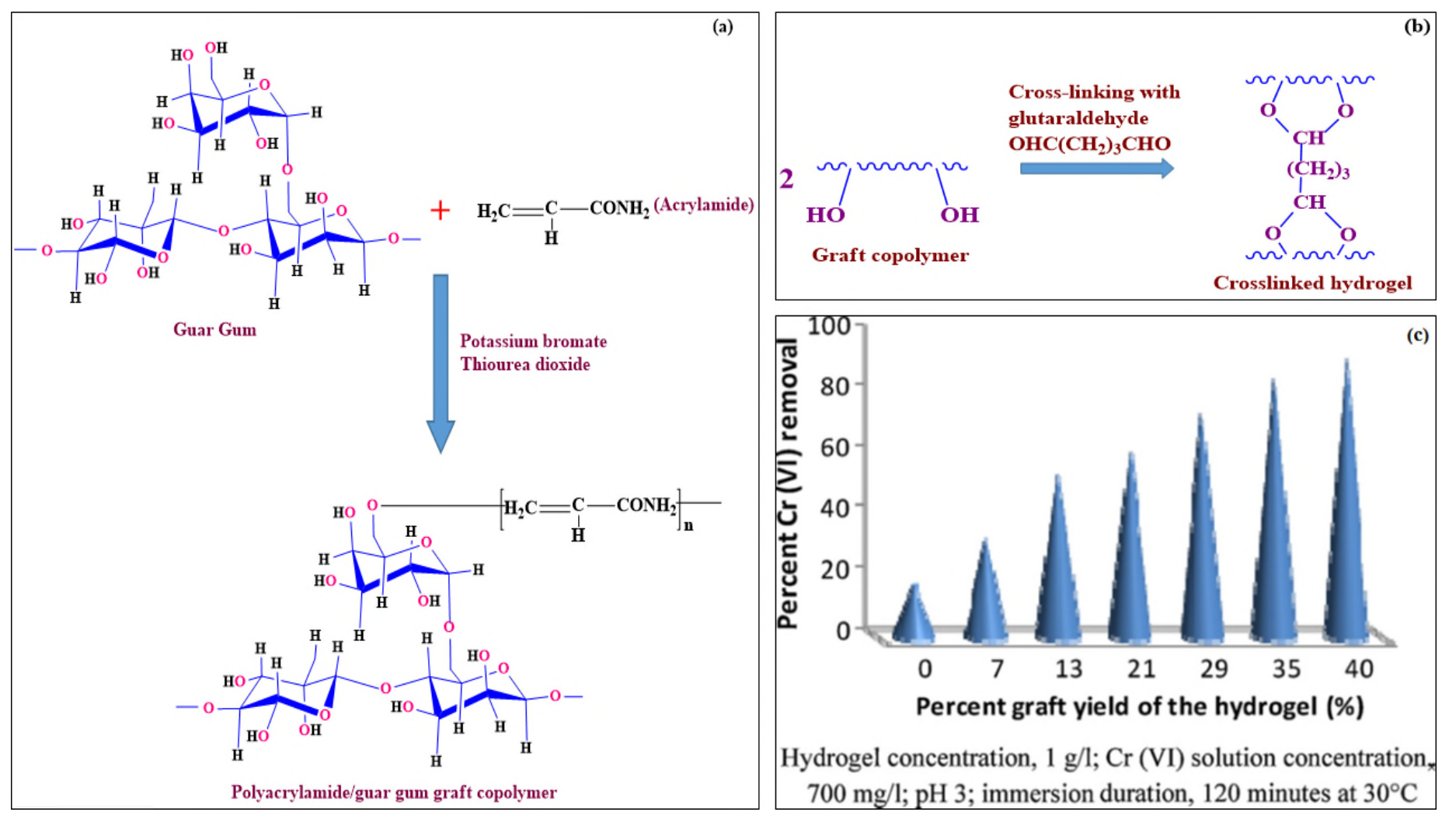

Figure 7. Possible mechanism for (a) synthesis of guar gum based polyacrylamide grafted copolymer, (b) crosslinking of guar gum based polyacrylamide grafted copolymer with glutaraldehyde and (c) effect of grafting on $\mathrm{Cr}$ (VI) ion adsorption [70]. Reprinted with permission from[70]. Copyright 2011 Elsevier. 
Table 1. Guar gum based hydrogels for removal of organic and inorganic pollutants.

\begin{tabular}{|c|c|c|c|c|}
\hline Sr. No. & Hydrogel Composites & pH & $\begin{array}{l}\text { Organic \& } \\
\text { Inorganic } \\
\text { Pollutants }\end{array}$ & References \\
\hline 1. & $\begin{array}{l}\text { Guar gum-poly(acrylic acid- } \\
\text { aniline) based interpenetrated } \\
\text { network hydrogel }\end{array}$ & 10 & Methylene blue & [64] \\
\hline 2. & $\begin{array}{c}\text { Guar gum-polyacrylamide } \\
\text { network hydrogel }\end{array}$ & 7 & $\begin{array}{c}\text { Crystal violet and } \\
\text { Azure B }\end{array}$ & [65] \\
\hline 3. & $\begin{array}{c}\text { Guar gum based acrylic acid } \\
\text { hydrogel }\end{array}$ & 10 & Methylene blue & [66] \\
\hline 4. & Guar gum/borax hydrogel & $\begin{array}{l}\text { Maximum } \\
\text { at } 9\end{array}$ & Aniline dye & [67] \\
\hline 5. & $\begin{array}{l}\text { Guar gum based bentonite clay } \\
\text { hydrogel }\end{array}$ & 2 & $\mathrm{Cr}(\mathrm{VI})$ & [68] \\
\hline 6. & $\begin{array}{c}\text { Guar gum-polyacrylamide } \\
\text { network hydrogel }\end{array}$ & $\begin{array}{l}\text { Maximum } \\
\text { at } 7\end{array}$ & $\begin{array}{c}\mathrm{Cu}(\mathrm{II}), \mathrm{Ni}(\mathrm{II}), \mathrm{Pb} \\
(\mathrm{II}), \text { and } \mathrm{Zn}(\mathrm{II})\end{array}$ & [69] \\
\hline 7. & $\begin{array}{c}\text { Polyacrylamide/guar gum graft } \\
\text { copolymer hydrogel }\end{array}$ & 3 & $\mathrm{Cr}(\mathrm{VI})$ & [70] \\
\hline 8. & $\begin{array}{c}\text { Guar gum-cl-N,N-methylenebis } \\
\text { acrylamide hydrogel }\end{array}$ & 7 & $\mathrm{Cu}(\mathrm{II})$ & [71] \\
\hline 9. & $\begin{array}{c}\text { Guar gum based silica } \\
\text { nanocomposite hydrogel }\end{array}$ & 9 & $\mathrm{Cd}(\mathrm{II})$ & [72] \\
\hline
\end{tabular}


2018-09-24

Recent approaches in guar gum hydrogel synthesis for water purification

Thakur, Sourbh

Taylor and Francis

Sourbh Thakur, Bhawna Sharma, Ankit Verma, et al., Recent approaches in guar gum hydrogel synthesis for water purification. International Journal of Polymer Analysis and Characterization, Volume 23, Issue 7, 2018, pp. 621-632

https://doi.org/10.1080/1023666X.2018.1488661

Downloaded from Cranfield Library Services E-Repository 